\title{
Adsorption of heavy metal ions and azo dyes by crosslinked nanochelating resins based on poly(methylmethacrylate-co-maleic anhydride)
}

\author{
A. Masoumi, M. Ghaemy* \\ Polymer research laboratory, Faculty of Chemistry, University of Mazandaran, Babolsar, Iran
}

Received 24 August 2013; accepted in revised form 28 October 2013

\begin{abstract}
Chelating resins are suitable materials for the removal of heavy metals in water treatments. A copolymer, Poly(MMA-co-MA), was synthesized by radical polymerization of maleic anhydride (MA) and methyl methacrylate (MMA), characterized and transformed into multifunctional nanochelating resin beads $(80-150 \mathrm{~nm})$ via hydrolysis, grafting and crosslink reactions. The resin beads were characterized by swelling studies, field emission scanning electron microscopy (FESEM) and Fourier transform infrared spectroscopy (FTIR). The main purpose of this work was to determine the adsorption capacity of the prepared resins (swelling ratio $\sim 55 \%$ ) towards metal ions such as $\mathrm{Hg}^{2+}, \mathrm{Cd}^{2+}, \mathrm{Cu}^{2+}$ from water at three different $\mathrm{pH}$ values (3,6 and 9). Variations in $\mathrm{pH}$ and types of metal ions have not significantly affected the chelation capacity of these resins. The maximum chelation capacity of one of the prepared resin beads $\left(\mathrm{Co}-\mathrm{g}-\mathrm{AP}_{3}\right)$ for $\mathrm{Hg}^{2+}$ was $63,85.8$ and $71.14 \mathrm{mg} / \mathrm{g}$ at $\mathrm{pH} \mathrm{3,6}$ and 9, respectively. Approximately $96 \%$ of the metal ions could be desorbed from the resin. Adsorption capacity of these resins towards three commercial synthetic azo dyes was also investigated. The maximum adsorption of dye AY42 was $91 \%$ for the resin $\mathrm{Co}-\mathrm{g}-\mathrm{AP}_{3}$ at room temperature. This insures the applicability of the synthesized resins for industrial applications.
\end{abstract}

Keywords: industrial applications, nanochelating crosslinked resin, heavy metal removal, dye removal

\section{Introduction}

Industrial and domestic wastewater containing heavy metal ions are increasingly discharged into the environment, especially in developing countries. Unlike some organic pollutants, heavy metals are not biodegradable and cannot be metabolized or decomposed [1]. They are responsible for causing damages to the environment and can also easily enter the food chain through a number of pathways and adversely affecting the health of people [2]. Therefore, reliable methods are needed to detect and remove heavy metals in environmental and biological samples. The traditional methods commonly used for their removal from aqueous solution include ion-exchange [3], solvent extraction [4], chemical precipitation [5], nano-filtration [6,7], reverse osmosis [8], and adsorption [9-12]. Among these techniques, adsorption is generally preferred due to its high efficiency, low cost possibilities, easy handling, and also the availability of different adsorbents. Nowadays, among the various solid adsorbents, polymeric chelating resins are widely used in the removal of metal ions due to their high adsorption capacities and selectivity [13-17]. Several criteria such as specific and fast complexation of the metal ions as well as the reusability of the adsorbent are important in the design of metal-chelating polymers. Synthetic chemicals including dyes have been extensively used in many industries such as textile, plastic, leather tanning, paper production, food tech-

\footnotetext{
${ }^{*}$ Corresponding author, e-mail: ghaemy@umz.ac.ir

(C) BME-PT
} 
nology, etc. They are toxic to some aquatic organisms and are of serious health risk to human beings [18]. Many physical and chemical methods have been used for the treatment of chemical-containing effluents [19-22]. Adsorption methods have been invariably successful to decolorize textile effluents, although this application can be limited by the high cost of adsorbents. This work describes preparation and characterization of nanochelating resin beads for the removal of heavy-metal ions and azo dyes from water. For these reasons, we have focused our attention on the development of new class functionalized adsorbents based on the copolymer poly (MMA-co-MA). To produce efficient metal-complexing ligand, different functional groups such as carboxylate and amine were introduced into the network structure of this copolymer via hydrolysis, grafting and crosslink reactions. Characterization of the chelating resins was carried out by swelling tests, FT-IR, XRD, AFM and SEM. The results of adsorption of $\mathrm{Hg}^{2+}, \mathrm{Cd}^{2+}$ and $\mathrm{Cu}^{2+}$ ions and synthetic azo dyes such as yellow 42 (AY42), red 151 (AR151) and blue 9 (MB9) by these resin beads from water are reported here. Desorption of the metal ions from the pre-adsorbed resins was also examined using $\mathrm{HCl}$ solution.

\section{Experimental}

\subsection{Materials}

Benzoyl peroxide (BPO), ethylenediamine (ED), diethylenetriamine (DETA), triethylenetetramine (TETA), (MMA), (MA), 2-aminopyridine (AP), triethylamine (TEA) and solvents were purchased from Fluka Co. (Germany). Copper chloride $\left(\mathrm{CuCl}_{2} \cdot 2 \mathrm{H}_{2} \mathrm{O}\right)$, mercury chloride $\left(\mathrm{HgCl}_{2}\right)$, cadmium chloride $\left(\mathrm{CdCl}_{2}\right)$, and dyes such as acid yellow 42 (AY42), acid red 151 (AR151) and mordant blue 9 (MB9) were purchased from Aldrich-Sigma Co. (Germany). All the chemicals and reagents were analytical grade and used as received without further purification. $\mathrm{pH}$ adjustments were performed with $\mathrm{HCl}$ and $\mathrm{NaOH}$ solutions.

\subsection{Synthesis}

(a) Synthesis of Poly(MMA-co-MA) was carried out via free-radical polymerization of (MA) and (MMA) in the presence of benzoyl peroxide (BPO) as an initiator and under argon atmosphere according to the procedure given in liter- ature with slight modification [23]. Briefly, in a $250 \mathrm{~mL}$ three-necked round bottom flask equipped with a magnetic stirrer, a condenser and an inlet for inert gas, $2.33 \mathrm{~mL}(0.020 \mathrm{~mol})$ MMA, $2.0 \mathrm{~g}(0.020 \mathrm{~mol}) \mathrm{MA}$, and $50 \mathrm{~mL}$ THF were placed. Then the reaction mixture was degassed for $30 \mathrm{~min}$ by argon to remove oxygen from the solution. BPO (1 wt $\%)$ was added to the reaction mixture and refluxed under these conditions for $8 \mathrm{~h}$. Finally the copolymer was precipitated by adding the reaction mixture into the nonsolvent of methanol and water $(1: 2, \mathrm{v}: \mathrm{v})$. The obtained white precipitate was washed thoroughly with water and then dried under vacuum at $80^{\circ} \mathrm{C}$ (yield $=96 \%$ ).

(b) The graft copolymer (Co-g-AP) was prepared by mixing a mole ratio of 1:0.5 of poly(MMAco-MA):AP in $50 \mathrm{~mL}$ THF in a $100 \mathrm{~mL}$ flask equipped with a magnetic stirrer, a condenser and an inlet for inert gas. Then, $0.5 \mathrm{~mL}$ $(0.004 \mathrm{~mol})$ TEA was added as a catalyst and the reaction mixture was refluxed with stirring for $4 \mathrm{~h}$. The solid product was formed by adding the reaction mixture into n-hexane. After filtration, the solid product was washed by n-hexane several times and then dried in a vacuum oven at $80^{\circ} \mathrm{C}$ (yield $=95 \%$ ).

(c) The hydrolyzed copolymer (Co-Hyd) was prepared by adding $1 \mathrm{~g}$ poly(MMA-co-MA) and $15 \mathrm{~mL} \mathrm{NaOH}(2 \mathrm{M})$ into a $100 \mathrm{~mL}$ flask equipped with a magnetic stirrer, a condenser and an inlet for inert gas. The mixture was stirred at room temperature for 7 hours until a clear homogeneous solution was formed. The hydrolyzed product was recovered as precipitate from basic solution by addition of $\mathrm{HCl}(1 \mathrm{M})$ solution. The precipitate was separated by filtration, washed several times with distilled water and then dried under vacuum at $80^{\circ} \mathrm{C}$ for $12 \mathrm{~h}$.

(d) The crosslinked resin beads (Co-g-AP ${ }_{1}, \mathrm{Co}-\mathrm{g}-$ $\mathrm{AP}_{2}, \mathrm{Co}-\mathrm{g}-\mathrm{AP}_{3}$ ) were prepared in THF by the reaction between poly(MMA-co-MA), AP as a grafting agent and a crosslink agent such as ED, DETA or TETA with a mole ratio of 1:0.5:0.25, respectively. $0.5 \mathrm{~mL}(0.004 \mathrm{~mol})$ TEA was used as a catalyst of the reaction. The mixture was refluxed for $3 \mathrm{~h}$ under inert gas with stirring using an ultrasonic water bath. A solid precipitate was formed as the reaction proceeded which 
was finally filtered, washed several times with $\mathrm{THF}$, and dried in a vacuum oven at $80^{\circ} \mathrm{C}$ for $12 \mathrm{~h}$. The yields were in the range of $94-98 \%$.

\subsection{Adsorption studies}

To investigate the tendency of the chelating resin beads for the removal of heavy metal ions such as $\mathrm{Cu}^{2+}, \mathrm{Cd}^{2+}$ and $\mathrm{Hg}^{2+}$ in aqueous solutions, constant weight of dried adsorbents were used in all batch experiments. Extraction of metal ions was carried out individually by using their chloride salts, $\mathrm{CuCl}_{2} \cdot 2 \mathrm{H}_{2} \mathrm{O}, \mathrm{CdCl}_{2}$ and $\mathrm{HgCl}_{2}$. All experiments were performed at room temperature by using mixture of $50 \mathrm{mg}$ beads and $50 \mathrm{~mL}$ metal ion solution (initial concentration: $100 \mathrm{mg} / \mathrm{L}$ ) in separate flasks which were stirred magnetically for $24 \mathrm{~h}$. The suspensions were brought to the desired $\mathrm{pH}(3,6,9)$ by adding $\mathrm{NaOH}(0.1 \mathrm{M})$ and $\mathrm{HCl}(0.1 \mathrm{M})$. After the adsorption was complete, the mixture was filtered, and the residual metal-ion content in the filtrate was determined by AAS. The amount of metal ion adsorbed into the unit of the chelating resin i.e. the adsorption capacity ( $Q$, in $\mathrm{mmol} \cdot \mathrm{g}^{-1}$ polymer) was calculated on the basis of Equation (1):

$Q=\frac{\left(C_{0}-C_{\mathrm{A}}\right) \cdot V}{W}$

where $C_{0}$ and $C_{\mathrm{A}}$ are the concentration $(\mathrm{mmol} / \mathrm{L})$ of metal ion in the initial solution and in the aqueous phase after adsorption, respectively, $V$ is the volume of the aqueous phase $(L)$ and $W$ is the weight of the adsorbent $(0.05 \mathrm{~g})$. The efficiency for ions adsorption from the solution $(R[\%])$ was calculated using Equation (2):

$R=\frac{C_{0}-C_{\mathrm{A}}}{C_{0}} \cdot 100$

\subsection{Desorption behavior}

For the desorption experiment, the chelating resin beads which had been adsorbed with the metal ions according to the procedure set-forth in the above section was used. The desorption of metal ions was carried out in $25 \mathrm{~mL}$ of $0.2 \mathrm{M} \mathrm{HCl}$ solution [24], while the mixture was stirred at room temperature for $1 \mathrm{~h}$. After filtration, the metal ion concentration in the aqueous phase was measured by AAS. The desorption ratio $(D[\%])$ was calculated by using Equation (3):
$D[\%]=\frac{A}{B} \cdot 100$

where $A$ is the amount of metal ions desorbed to the elution medium $[\mathrm{mg}]$ and $B$ is the amount of metal ions adsorbed on the resin [mg].

\subsection{Dyes removal}

To investigate the tendency of the chelating resin beads for the removal of dyes in aqueous solutions, constant weight of dried adsorbents were used in all batch experiments. The chemical structures of the azo dyes are shown in Figure 1. $0.05 \mathrm{~g}$ of the resin beads (Co-g-AP 3 , MMA-Co-MA, and Co-Hyd) and $10 \mathrm{~mL}$ aqueous solution of a dye such as AY42, AR151and MB9 (initial concentration, $100 \mathrm{mg} / \mathrm{L}$ ) were shaken in a shaker at room temperature for $12 \mathrm{~h}$ without $\mathrm{pH}$ adjustment. The concentration of dye in the filtrate was determined by measuring the maximum absorption intensity of each dye at the corresponding wavelength using a UV-vis spectrophotometer $\left(\lambda_{\max }=408 \mathrm{~nm}\right.$ for AY42, $\lambda_{\max }=500 \mathrm{~nm}$ for AR151 and $\lambda_{\max }=533 \mathrm{~nm}$ for MB9) and the following Beer-Lambert law (Equation (4)):

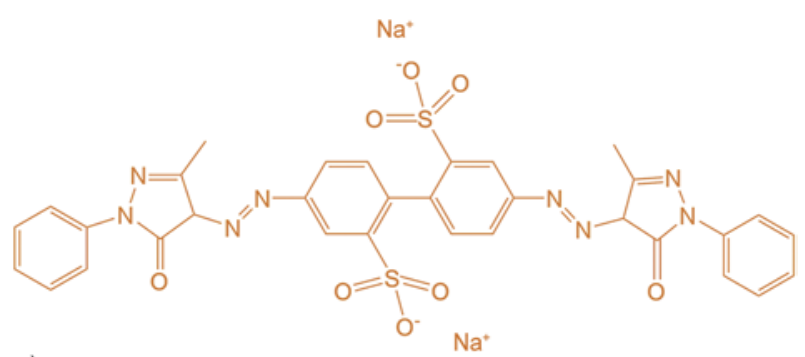

a)

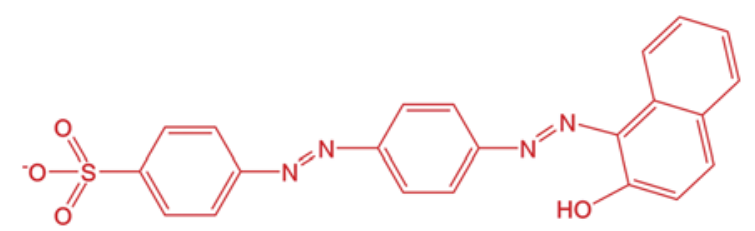

b)

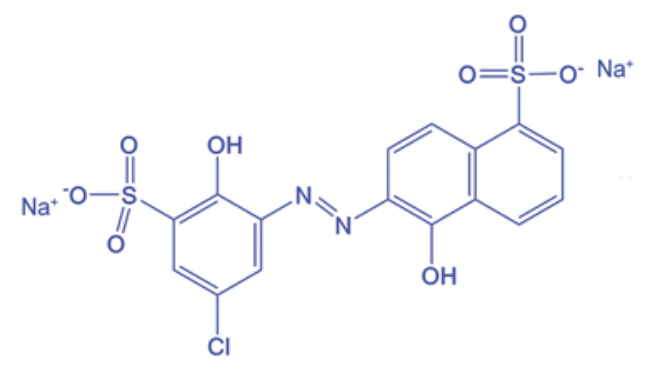

c)

Figure 1. Chemical structural of the tested dyes; AY42 (a), AR151 (b) and MB9 (c) 
$A_{0}-A=\varepsilon b\left(C_{0}-C\right)$

where $A$ is the absorption of dye at a given wavelength, $\varepsilon$ is molar absorptivity, unique to each molecule and varying with wavelength, $b$ is the path length through the solution that the light has to travel $(1 \mathrm{~cm})$, and $C_{0}(100 \mathrm{mg} / \mathrm{L})$ and $C$ is the concentration of dye in the solution before and after adsorption, respectively. The sorption percentage of the chelating resin was calculated using Equation (5):

$R[\%]=\frac{W}{W_{0}} \cdot 100$

where $W$ is the amount of adsorbed dye and $W_{0}$ the initial amount of dye.

\subsection{Measurements}

FT-IR analysis was carried out on a Bruker Tensor 27 spectrometer (Bruker, Karlsruhe, Germany). Xray diffraction $(\mathrm{XRD})$ patterns were obtained on a RigakuD/Max-2550 powder diffractometer with a scanning speed of $5^{\circ} \cdot \mathrm{min}^{-1}$ in the $2 \theta$ range of 10 $70^{\circ}$. The surface morphology of the beads was examined by using field emission scanning electron microscopy (FESEM) (Model: Hitachi S4160). A fragment of the dried bead was mounted on a FESEM sample mount and was sputter coated with gold for $2 \mathrm{~min}$, and then was mounted in FESEM and scanned at the desired magnification. A PHS-3C pH-meter (Shanghai, Tianyou) was used for $\mathrm{pH}$ measurements. The concentration of metal ions in the solution was measured by use of a flame atomic absorption spectrophotometer (AAS) (Hewlett-Packard 3510). Atomic force microscopy (AFM, Easy Scan 2 Flex AFM, Swiss Co.) was also used to investigate the surface phase and topography of the resin beads before and after the sorption process. The concentration of dye in the filtrate was measured using a UV-visible spectrophotometer. The gel permeation chromatography (GPC) measurements were conducted at $30^{\circ} \mathrm{C}$ with a Perkin-Elmer instrument equipped with a differential refractometer detector. The columns used were packed with a polystyrene/ divinylbenzene copolymer (PL gel MIXED-B from Polymer Laboratories) and THF was used as fluent at a flow rate of $1 \mathrm{~mL} / \mathrm{min}$. Calibration of the instrument was performed with monodisperse polystyrene standards. Water absorption measurements of the chelating resins were determined gravimetrically in distilled water at room temperature. Briefly, $0.2 \mathrm{~g}$ dry resin beads (Co-g-AP, Co-g-AP 1, Co-g-AP 2 , Co$\mathrm{g}-\mathrm{AP}_{3}$, and $\mathrm{Co}-\mathrm{Hyd}$ ) were placed in separate $50 \mathrm{~mL}$ vials containing distilled water for 3 days. The beads were taken out from the water at different times, wiped using a filter paper, and weighed. The weight difference before and after immersion was determined and used for calculation of the swelling ratio.

\section{Results and discussion \\ 3.1. Characterization and properties of the chelating resins}

The FT-IR spectrum of poly(MMA-co-MA), Figure $2 \mathrm{a}$, showed characteristic absorption bands of anhydride at 1747,1809 and $1856 \mathrm{~cm}^{-1}$ and of ester group in the MMA repeating unit at $1724 \mathrm{~cm}^{-1}$. The number and weight average molar masses $\left(M_{\mathrm{n}}\right.$ and $M_{\mathrm{w}}$ ) of this copolymer were determined by GPC were $5.096 \cdot 10^{3}$ and $9.34 \cdot 10^{3} \mathrm{~g} / \mathrm{mol}$, respectively, with distribution index of 1.83. Earlier studies have indicated that carboxylic acid and amide functional groups in polymer backbone provide more adsorption sites for heavy metal ions in wastewater. In order to obtain chelating resins as adsorbents of heavy metals with satisfactory adsorption capacity, following transformations were performed: (1) poly (MMA-co-MA) was hydrolyzed with $\mathrm{NaOH}$ (2 M) to form carboxylate ions which then neutralized by $\mathrm{HCl}$ to form $-\mathrm{COOH}$ groups along the copolymer chains, (2) poly(MMA-co-MA) was reacted with

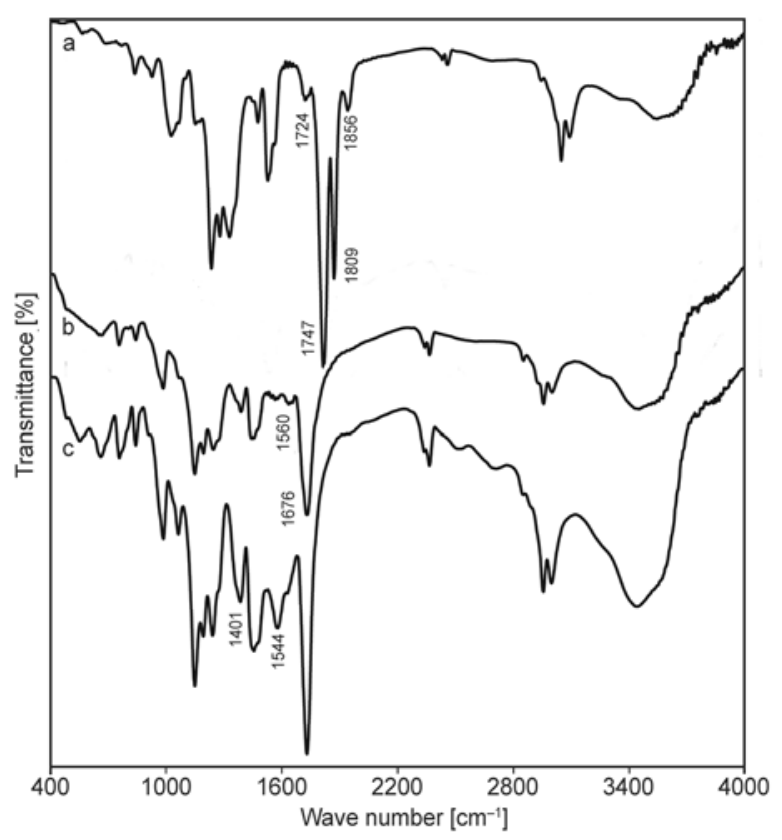

Figure 2. Representative FT-IR spectra of poly(MMA-coMA) (a), Co-g-AP 3 (b) and metal-resin complex $\left\{\mathrm{Hg}-\left(\mathrm{Co}-\mathrm{g}-\mathrm{AP}_{3}\right)\right\}$ (c) 
AP to form an alkylamide linkage and a carboxylic acid group, and (3) poly(MMA-co-MA) was reacted with AP and a crosslink agent such as ED, DETA, and TETA to form a network structure with many adsorption sites for metal ions. Comparison of the FT-IR spectra of poly(MMA-co-MA) and Co-g- $\mathrm{AP}_{3}$, as shown in Figure $2 \mathrm{a}$ and $2 \mathrm{~b}$, indicates that characteristic bands of the anhydride linkage in poly(MMA-co-MA) at 1747, 1809 and $1856 \mathrm{~cm}^{-1}$ disappeared after reaction with TETA and the formed amide linkage (-CO-NH-) showed absorption band at $\sim 1676 \mathrm{~cm}^{-1}$. To investigate the effect of chemical reactions in the copolymer matrix, the phase morphology was studied using SEM. Figure $3 a-3 c$ shows representative SEM images of Co-g-AP, Co$\mathrm{g}-\mathrm{AP}_{3}$ and $\mathrm{Co}-\mathrm{Hyd}$. As can be seen in these figures, the roughness of the surface and particularly the porous surface after hydrolysis, Figure $3 \mathrm{c}$, should be considered as a factor providing chelating ability for the resins. On that basis, the adsorbents present an adequate morphology with disordered distribution of sizes which can be the main reason of their high surface ability for the removal of metal ions. To observe morphological properties such as surface porosity, texture and roughness, micrographs of the surface and cross section of $\mathrm{Co}-\mathrm{g}-\mathrm{AP}_{3}$ before and after metal ion adsorption were registered by using AFM. Figure 3d shows smoother surface of Co-g$\mathrm{AP}_{3}$ before metal ion adsorption while Figure $3 \mathrm{e}$ reveals a predominantly hill-valley-structured surface with irregular pores of nanoscale topography after metal ion adsorption. The roughness can also be seen in 3D images of the surface of metal ion adsorbed sample with their histograms show size distribu-

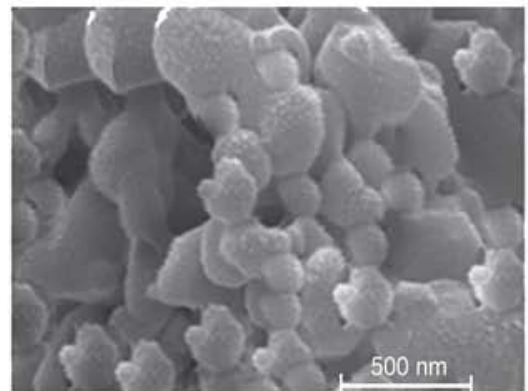

a)

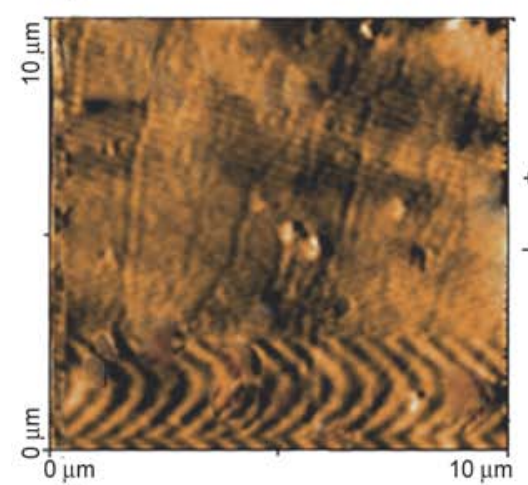

d)

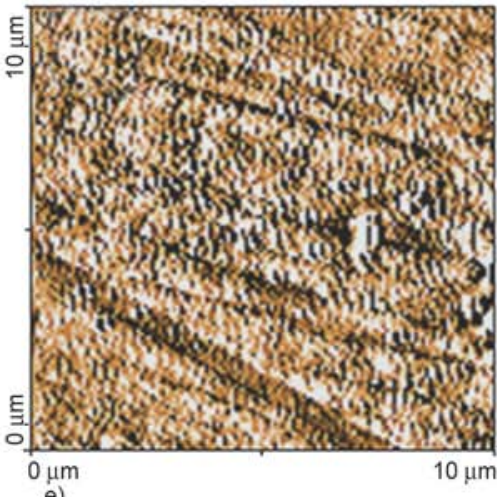

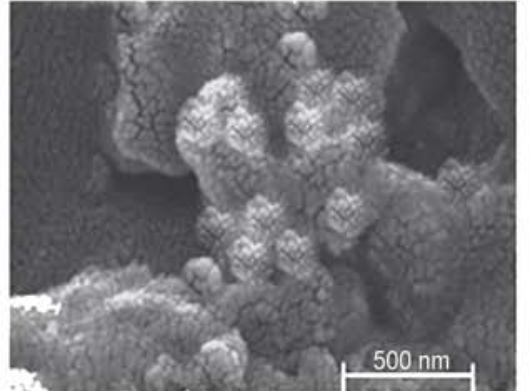

b)

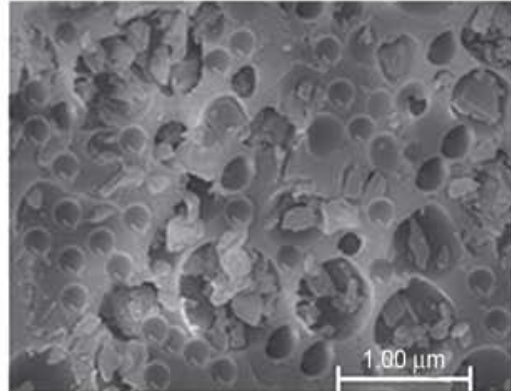

c)
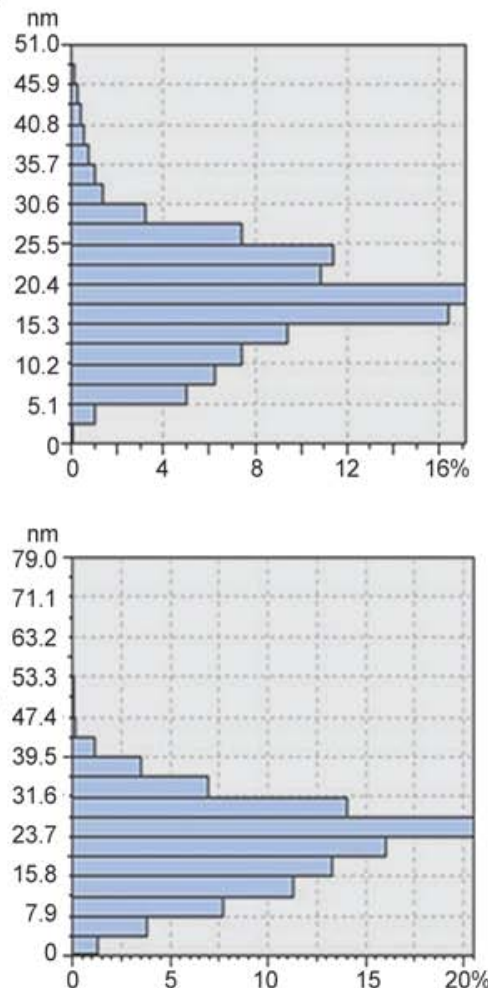

Figure 3. Representative FESEM images of Co-g-AP (a), Co-g-AP 3 (b) and Co-Hyd (c). AFM images of Co-g-AP before (d) and after (e) $\mathrm{Hg}^{2+}$ ion adsorption 


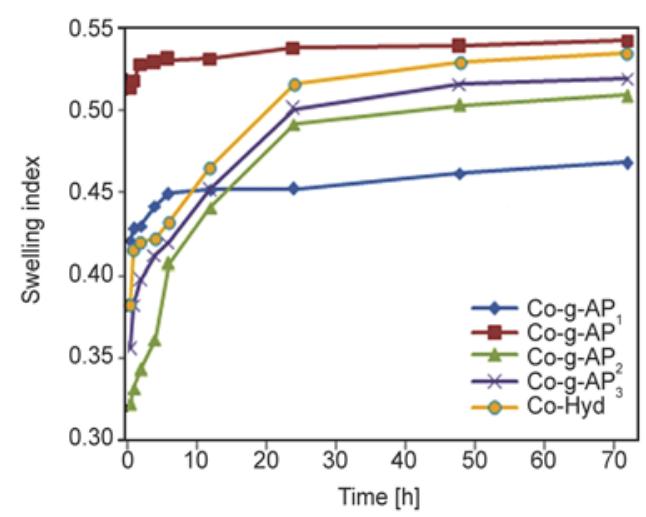

Figure 4. Water uptake of the chelating resins

tions. The average size for the particles of Co-g$\mathrm{AP}_{3}$ before adsorption is in the range of $15-17 \mathrm{~nm}$ and after metal ion adsorption is in the range of 20 $28 \mathrm{~nm}$, respectively. The crosslinked beads are hydrophilic matrices, i.e., hydrogels; therefore they do not dissolve in aqueous media, but do swell, depending on the degree of crosslinking and on the hydrophilicity of the matrix. The equilibrium swelling ratio of the resin beads are shown in Figure 4. Several possible factors are contributing in water absorption of the beads such as incorporation of hydrophilic amino and amide groups into the polymer matrix which increases water absorption and introduction of hydrophobic $-\mathrm{CH}_{2}-$ units into the polymer structure via crosslink agent such as TETA which reduces water uptake of the resin. As can be seen in Figure 4, the copolymers Co-g-AP and Co-Hyd showed the highest water absorption. These two copolymers are not crosslinked and they are open systems with highly hydrophilic groups of carboxylic acids. The water absorption of three crosslinked copolymers showed order of Co-g-AP 3 $>\mathrm{Co}$-g- $\mathrm{AP}_{2}>\mathrm{CO}-\mathrm{g}-\mathrm{AP}_{1}$ which depended on the chemical structure of the curing agent (ED, DETA and TETA, respectively) and the network structure. The XRD patterns of all copolymers showed only a broad diffraction hump at about $2 \theta=15-20$ indicating the amorphous nature of the prepared resin beads.

\subsection{Adsorption of heavy metal ions}

In this research, the FT-IR spectroscopy was used to monitor the structural changes take place in the chelating resins as a result of metal-ion complexation. Therefore, the first information about the structural changes such as shift or elimination of a certain band present in the starting resin as well as the appearance of new bands, caused by the complexation of the resin with metal ions, was provided by the FT-IR spectra. The bonding mode of $\mathrm{Hg}^{2+}$ to chelating resin was examined by comparing the FTIR spectra of poly(MMA-co-MA) and Co-g- $\mathrm{AP}_{3}$ with the spectrum of $\left[\mathrm{Hg}-\left(\mathrm{Co}-\mathrm{g}-\mathrm{AP}_{3}\right)\right]$ complex. As shown in Figure 2c, the FT-IR spectrum of Hg-(Co$\left.\mathrm{g}-\mathrm{AP}_{3}\right)$ is quite different from the spectrum of poly (MMA-co-MA) in Figure 2a. Two strong absorption bands at 1401 and $1544 \mathrm{~cm}^{-1}$ are observed in the spectrum of $\left[\mathrm{Hg}-\left(\mathrm{Co}-\mathrm{g}-\mathrm{AP}_{3}\right)\right]$ complex, which are assigned to the symmetric (vs, $\mathrm{COO}^{-}$) and asymmetric (vas, $\mathrm{COO}^{-}$) vibration absorption of the carboxylic groups, respectively [25]. The shift of FTIR peak for the carbonyl group of carboxylate could indicate whether the bonding between the ligand and metal ion was covalent or ionic [26]. In this study, there is small shift towards higher frequency which can be taken as evidence for formation of covalent bond between metal ions and carbonyl groups. The absorption bands characteristic of the aromatic AP in the resin matrix are observed at 1032, 914,767 , and $703 \mathrm{~cm}^{-1}$ which were not influenced by the metal complexation. The adsorption capacity of the chelating resin beads for the tested metal ions of $\mathrm{Cu}^{2+}, \mathrm{Cd}^{2+}$ and $\mathrm{Hg}^{2+}$ at $\mathrm{pH} \mathrm{3,6}$ and 9 are shown in Figure 5. The results demonstrated a relatively weak dependency of metal ions sorption on the $\mathrm{pH}$ variations. A relatively high adsorption of about $60-80 \%$ was observed at various $\mathrm{pH}$ values for the tested metal ions by all the chelating resin beads. Adsorbents with carboxyl, sulfonic, and phosphonic groups on the surface, remove adsorbates through ion exchange, while those containing nitrogen such as amine, hydrazine, thioamide, and imidazoline groups, not only chelate cationic metal ions, but also adsorb anionic adsorbates through electrostatic interactions [27-29]. All the prepared resins have carboxylic acid and amine groups as potential ion exchange/complexing units. In the acidic conditions, the degree of protonation of amine groups affects their ability to bind metal ions. Therefore, the relatively high adsorption of metal ions in acidic conditions could be explained by the complex formation between $\mathrm{M}^{+2}$ and $-\mathrm{COOH}$ groups. The $-\mathrm{COOH}$ groups are formed as a result of reaction between anhydride of the copolymer and amine of the crosslink agent, and also can be due to hydrolysis of the ester linkage in the MMA repeating unit. As can be seen in Figure 5, the dependency of adsorption capacity of these resins on the $\mathrm{pH}$ value is related to the functional groups of adsorbent and 

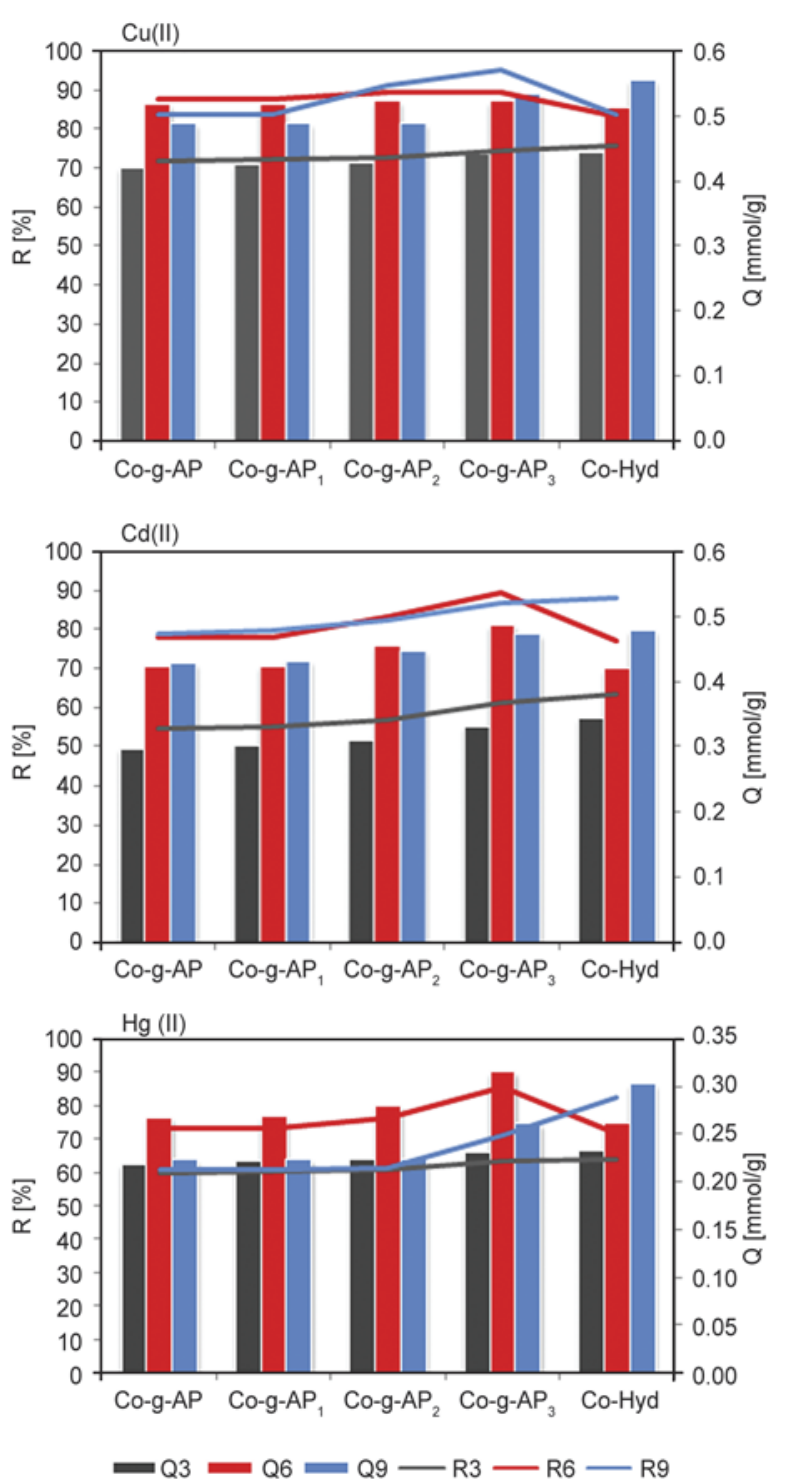

Figure 5. Effect of the initial $\mathrm{pH}$ of the testing solutions on the adsorption capacity $(Q)$ and percentage $(R$ $[\%])$ for the tested metal ions. Initial ion concentration $=100 \mathrm{mg} / \mathrm{L}$, sample dose $=5 \mathrm{mg} / 50 \mathrm{~mL}$, temperature $=25^{\circ} \mathrm{C}$, and contact time $=24 \mathrm{~h}$.

type of metal ion. For example, all the chelating resins adsorbed about $55 \%(Q=0.31 \mathrm{mmol} / \mathrm{g}) \mathrm{Cd}^{2+}$ at $\mathrm{pH} 3$ which increased to over $81 \%(Q=$ $0.46 \mathrm{mmol} / \mathrm{g}$ ) at $\mathrm{pH} 9$, while adsorption of $\mathrm{Cu}^{2+}$ was $73 \%(Q=0.42 \mathrm{mmol} / \mathrm{g})$ and $87 \%(Q=0.51 \mathrm{mmol} / \mathrm{g})$, respectively, at same $\mathrm{pH}$ values. Therefore, in general, a high affinity was observed for adsorption of the tested metal ions by all the prepared resins especially by Co-Hyd and Co-g- $\mathrm{AP}_{3}$ at various $\mathrm{pH}$. This can be due to presence of different metal ion adsorption sites such as carboxylate and amine groups in the copolymer matrix. The order of adsorption percentage changed as follows: $\mathrm{Co}-\mathrm{g}-\mathrm{AP}_{3} \geq \mathrm{Co}-\mathrm{Hyd}>$ Co-g-AP $>$ Co-g-AP $>$ Co-g-AP. The order of these

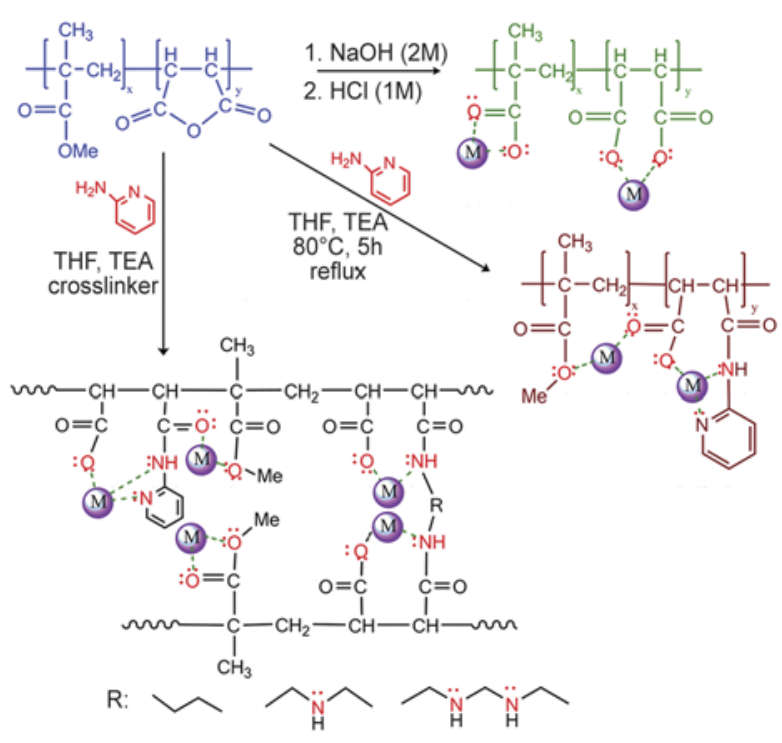

Figure 6. Illustration of metal-chelating resin complexes of Co-Hyd, Co-g-AP and the crosslinked chelating resin

three kinds of metal ion chelation on mass basis for the single component metal is $\mathrm{Cu}^{2+}>\mathrm{Cd}^{2+}>\mathrm{Hg}^{2+}$. This affinity trend is presented on the mass basis $[\mathrm{mg}]$ metal chelation per gram resin beads and these units are important in quantifying respective metal capacities in real terms. Incorporation of TETA as crosslinking agent, with long alkyl chain and four amine groups, into the resin structure has significantly increased the adsorption capacity of the network. The results show that the adsorption capacity with $\mathrm{Hg}^{2+}$ (at $\mathrm{pH}=6$ ) is $71.4 \mathrm{mg} / \mathrm{g}$ for Co-Hyd, $72.63 \mathrm{mg} / \mathrm{g}$ for Co-g-AP, $73 \mathrm{mg} / \mathrm{g}$ for Co-g-AP ${ }_{1}$, $76.3 \mathrm{mg} / \mathrm{g}$ for Co-g- $\mathrm{AP}_{2}$ and $85.8 \mathrm{mg} / \mathrm{g}$ for Co-g$\mathrm{AP}_{3}$. Figure 6 illustrates the metal ions binding onto the chelating resins. Adsorbents used in heavy metal ions removal are in particulate form in most of the cases. In the literature, different affinity sorbents with a wide range of adsorption capacities for heavy metal ions have been reported. Shreedhara-Murthy and Ryan found 5-27 mg/g Cu(II) removal by cellulose dithiocarbamate resins [30]. Roozemond showed $32 \mathrm{mg} / \mathrm{g} \mathrm{Cu}(\mathrm{II})$ with pyrazole-containing poly(styrene-divinyl-benzene) sorbents [31]. Say et al. [32] achieved 714.1, 468.8 and $639.4 \mathrm{mg} / \mathrm{g}$ adsorption capacities for $\mathrm{Pb}(\mathrm{II}), \mathrm{Cr}(\mathrm{III})$ and $\mathrm{Cd}(\mathrm{II})$, respectively, with poly(HEMA-MAH) beads. Kara et al. [33] have prepared poly(EGDMA-VIM) beads and found the chelation capacities of these beads were 69.4 and $114.8 \mathrm{mg} / \mathrm{g}$ for $\mathrm{Cd}(\mathrm{II})$ and $\mathrm{Pb}(\mathrm{II})$, respectively. Duran et al. [34] have prepared [poly (VP-PEGMA-EGDMA)] beads and found the chela- 
tion capacities of these beads were $18.23,16.50$, 15.81 and $18.25 \mathrm{mg} / \mathrm{g}$ for $\mathrm{Pb}(\mathrm{II}), \mathrm{Cd}(\mathrm{II}), \mathrm{Cr}(\mathrm{III})$, and $\mathrm{Cu}(\mathrm{II})$, respectively.

\subsection{Desorption of metal ions from the chelating resin}

The repeated use of the resins is an essential parameter in improving process economics. Desorption of metal ions from resin-metal ion complexes was carried out by $\mathrm{HCl}(0.2 \mathrm{M})$ treatment at room temperature and the amount of metal ions desorbed in 1 hour was measured. As shown in Figure 7, more than $96 \%$ of adsorbed metal ions are recovered in the acid leaching process indicating that chelation (i.e., binding of heavy metal ions with functional groups in resin) is completely reversible. In order to obtain the reusability of the resins, chelation-elution cycle was repeated successfully five times by using the same adsorbent and the results are shown in Figure 7.

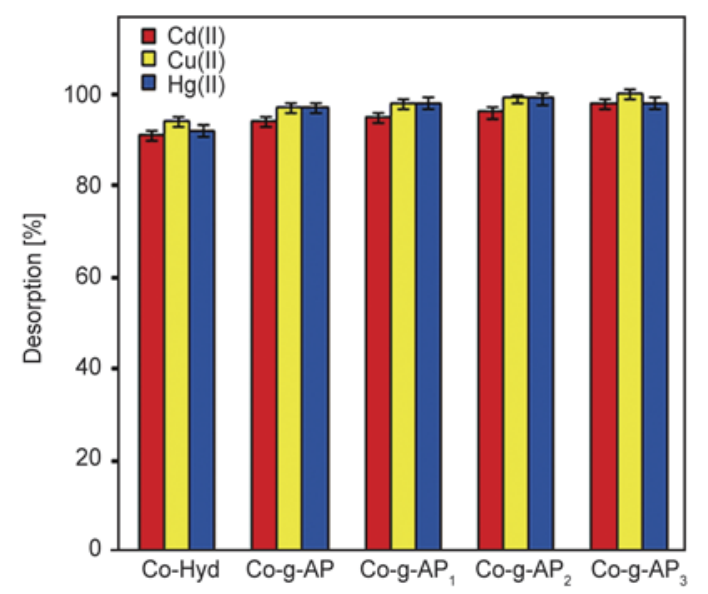

Figure 7. Desorption of $\mathrm{Hg}^{2+}$ ion from the chelating resins beads that had been preadsorbed, under conditions given in Figure 6, as a function of submersion time in $25 \mathrm{~mL}$ of $\mathrm{HCl}(0.2 \mathrm{M})$ solution for $1 \mathrm{~h}$ at $25^{\circ} \mathrm{C}$

\subsection{Dyes removal}

The adsorption of dyes with the prepared chelating resin beads was carried out by using three commercial azo dyes containing different functional groups such as $-\mathrm{N}=\mathrm{N}-$, chlorine, oxadiazine and sulfate (Figure 1). The results for the dyes adsorption are shown in Figure 8. The order for the dyes removal by the resins is: Co-g- $\mathrm{AP}_{3}>\mathrm{Co}-\mathrm{Hyd}>$ poly(MMAco-MA), indicating higher capacity for the crosslinked resin in comparison with the results obtained

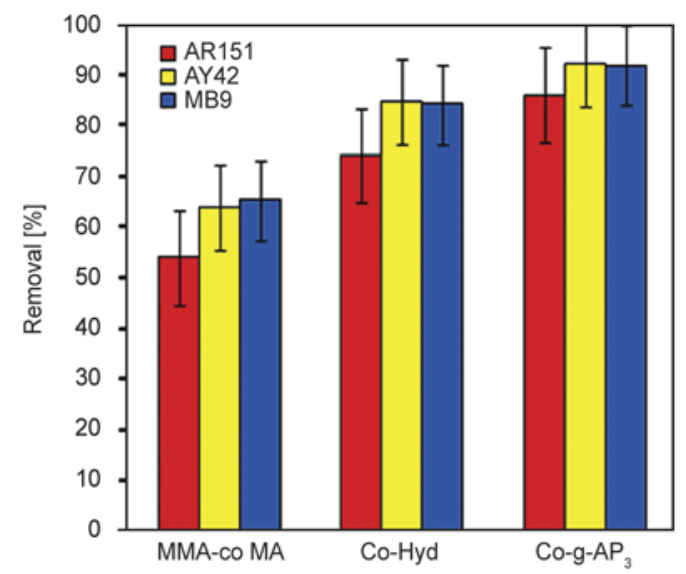

Figure 8. Dyes removal efficiency by the prepared resin beads; $(0.05 \mathrm{~g}$ of the chelating resin in $10 \mathrm{~mL}$ aqueous solution containing a dye with initial concentration $=100 \mathrm{mg} / \mathrm{L}$, at $25^{\circ} \mathrm{C}$ for $12 \mathrm{~h}$ without $\mathrm{pH}$ adjustment)

for the unmodified copolymer. This can be due to presence of network structure with different functional groups in the modified resin $\left(\mathrm{Co}-\mathrm{g}-\mathrm{AP}_{3}\right)$, which can accommodate large molecules and interact with the functional groups present in the dye molecules. Also, the relatively high adsorption percentage of Co-Hyd resin can be due to highly pores structure of this resin, as shown in Figure 3c.

\section{Conclusions}

Adsorption represents a potentially cost-effective way of eliminating toxic heavy metals from industrial wastewaters. Reusable polymer-based adsorbents have been recognized as a promising class of low-cost adsorbents for the removal of heavy-metal ions from aqueous waste streams. In this study, the reaction of AP and different crosslink agents with poly(MMA-co-MA) led to the synthesis of significantly capable chelating resins for the removal of heavy metal ions such as $\mathrm{Cu}^{2+}, \mathrm{Cd}^{2+}$ and $\mathrm{Hg}^{2+}$ from aqueous solution. These results suggest that the prepared chelating resin beads are good heavy metal ions adsorbents in various $\mathrm{pH}$ values and can have great potential applications in environmental protection. The affinity order of metal ions on a molar basis is as: $\mathrm{Cu}^{2+}>\mathrm{Cd}^{2+}>\mathrm{Hg}^{2+}$. The new adsorbents have higher adsorption properties than other adsorbents reported by some researchers. In addition, the capacity of dyes removal of the resin beads was investigated and the results showed that the adsorbed dye increased by using crosslinked resin. 


\section{References}

[1] Matsuto T., Jung C. H., Tanaka N.: Material and heavy metal balance in a recycling facility for home electrical appliances. Waste Management, 24, 425-436 (2004). DOI: $10.1016 /$ j.wasman.2003.12.002

[2] Srivastava N. K., Majumder C. B.: Novel biofiltration methods for the treatment of heavy metals from industrial wastewater. Journal of Hazardous Materials, 151, $1-8$ (2008).

DOI: $10.1016 /$ j.jhazmat.2007.09.101

[3] Vaaramaa K., Lehto J.: Removal of metals and anions from drinking water by ion exchange. Desalination, 155, 157-170 (2003).

DOI: $10.1016 / \mathrm{S} 0011-9164(03) 00293-5$

[4] Černá M.: Use of solvent extraction for the removal of heavy metals from liquid wastes. Environmental Monitoring and Assessment, 34, 151-162 (1995).

DOI: $10.1007 / \mathrm{BF} 00546029$

[5] Hu X., Li Y., Wang Y., Li X., Li H., Liu X., Zhang P.: Adsorption kinetics, thermodynamics and isotherm of thiacalix[4]arene-loaded resin to heavy metal ions. Desalination, 259, 76-83 (2010). DOI: $10.1016 /$ j.desal.2010.04.032

[6] Al-Rashdi B. A. M., Johnson D. J., Hilal N.: Removal of heavy metal ions by nanofiltration. Desalination, 315, 2-17 (2013).

DOI: $10.1016 /$ j.desal.2012.05.022

[7] Ozaki H., Sharma K., Saktaywin W.: Performance of an ultra-low-pressure reverse osmosis membrane (ULPROM) for separating heavy metal: effects of interference parameters. Desalination, 144, 287-294 (2002). DOI: 10.1016/S0011-9164(02)00329-6

[8] Petersková M., Valderrama C., Gibert O., Cortina J. L.: Extraction of valuable metal ions (Cs, $\mathrm{Rb}, \mathrm{Li}, \mathrm{U})$ from reverse osmosis concentrate using selective sorbents. Desalination, 286, 316-323 (2012).

DOI: $10.1016 /$ j.desal.2011.11.042

[9] Soleimani Lashkenari M., Davodi B., Ghorbani M., Eisazadeh H.: Use of core-shell polyaniline/polystyrene nanocomposite for removal of $\mathrm{Cr}(\mathrm{VI})$. High Performance Polymers, 24, 345-355 (2012). DOI: $10.1177 / 0954008311436222$

[10] Li L., Li Y., Luo X., Deng J., Yang W.: Helical poly( $N$ propargylamide)s with functional catechol groups: Synthesis and adsorption of metal ions in aqueous solution. Reactive and Functional Polymers, 70, 938943 (2010).

DOI: $10.1016 /$ j.reactfunctpolym.2010.09.006

[11] Jitjaicham S., Kampalanonwat P., Supaphol P.: Metal adsorption behavior of 2,4-dinitrophenyl hydrazine modified polyacrylonitrile nanofibers. Express Polymer Letters, 7, 832-841 (2013).

DOI: $10.3144 /$ expresspolymlett.2013.80
[12] Coşkun R., Soykan C., Saçak M.: Removal of some heavy metal ions from aqueous solution by adsorption using poly(ethylene terephthalate)-g-itaconic acid/acrylamide fiber. Reactive and Functional Polymers, 66, 599-608 (2006).

DOI: $10.1016 /$ j.reactfunctpolym.2005.10.012

[13] Sankar R., Sasidaran M., Kaliyappan T.: Synthesis, characterization, thermal and chelation properties of new polymeric hydrazone based on 2,4-dihydroxy benzaldehyde. High Performance Polymers, 23, 32-39 (2011).

DOI: $10.1177 / 0954008310381148$

[14] Sasidaran M., Sankar R., Kandasamy P., Vijayalakshmi S., Kaliyappan T.: Chelating and biological properties of an azo polymer resin: Synthesis, characterization and its application. High Performance Polymers, 23, 602-609 (2011). DOI: $10.1177 / 0954008311428531$

[15] Dinu M. V., Dragan E. S.: Heavy metals adsorption on some iminodiacetate chelating resins as a function of the adsorption parameters. Reactive and Functional Polymers, 68, 1346-1354 (2008).

DOI: $10.1016 /$ j.reactfunctpolym.2008.06.011

[16] Vasconcelos H. L., Fávere V. T., Gonçalves N. S., Laranjeira M. C. M.: Chitosan modified with Reactive Blue 2 dye on adsorption equilibrium of $\mathrm{Cu}$ (II) and $\mathrm{Ni}(\mathrm{II})$ ions. Reactive and Functional Polymers, 67, 1052-1060 (2007).

DOI: $10.1016 /$ j.reactfunctpolym.2007.06.009

[17] Takagi K., Miwa S., Yuki Y.: Synthesis of poly(triazinylstyrene) containing nitrogen-based ligand and function as metal ion adsorbent and oxidation catalyst. Reactive and Functional Polymers, 66, 1718-1724 (2006).

DOI: $10.1016 /$ j.reactfunctpolym.2006.07.005

[18] Ahamed M. E. H., Mbianda X. Y., Mulaba-Bafubiandi A. F., Marjanovic L.: Ion imprinted polymers for the selective extraction of silver(I) ions in aqueous media: Kinetic modeling and isotherm studies. Reactive and Functional Polymers, 73, 474-483 (2013). DOI: $10.1016 /$ j.reactfunctpolym.2012.11.011

[19] Wang C-C., Wang C-C.: Adsorption characteristics of metal complexes by chelated copolymers with amino group. Reactive and Functional Polymers, 66, 343-356 (2006).

DOI: $10.1016 /$ j.reactfunctpolym.2005.08.011

[20] Vasconcelos H. L., Camargo T. P., Gonçalves N. S., Neves A., Laranjeira M. C. M., Fávere V. T.: Chitosan crosslinked with a metal complexing agent: Synthesis, characterization and copper(II) ions adsorption. Reactive and Functional Polymers, 68, 572-579 (2008). DOI: $10.1016 /$ j.reactfunctpolym.2007.10.024

[21] Huang J., Zhang K.: The high flux poly (m-phenylene isophthalamide) nanofiltration membrane for dye purification and desalination. Desalination, 282, 1926 (2011).

DOI: $10.1016 /$ j.desal.2011.09.045 
[22] Teng M-Y., Lin S-H.: Removal of methyl orange dye from water onto raw and acidactivated montmorillonite in fixed beds. Desalination, 201, 71-81 (2006). DOI: 10.1016/j.desal.2006.03.521

[23] Yan B., Wang Q.: Covalently bonded assembly and photoluminescent properties of rare earth/silica/poly (methyl methacrylate-co-maleic anhydride) hybrid materials. Journal of Photochemistry and Photobiology A: Chemistry, 197, 213-219 (2008).

DOI: 10.1016/j.jphotochem.2007.12.025

[24] El-Hag Ali A., Shawky H. A., Abd El Rehim H. A., Hegazy E. A.: Synthesis and characterization of PVP/AAc copolymer hydrogel and its applications in the removal of heavy metals from aqueous solution. European Polymer Journal, 39, 2337-2344 (2003). DOI: 10.1016/S0014-3057(03)00150-2

[25] Albunia A. R., Rizzo P., Guerra G., Torres F. J., Civalleri B., Zicovich-Wilson C. M.: Uniplanar orientations as a tool to assign vibrational modes of polymer chain. Macromolecules, 40, 3895-3897 (2007). DOI: $10.1021 / \mathrm{ma} 070380+$

[26] Wang C-C., Chang C-Y., Chen C-Y.: Study on metal ion adsorption of bifunctional chelating/ion-exchange resins. Macromolecular Chemistry and Physics, 202, 882-890 (2001).

DOI: $10.1002 / 1521-3935(20010301) 202: 6<882:: A I D-$ MACP882>3.0.CO;2-K

[27] Dinu M. V., Dragan E. S.: Evaluation of $\mathrm{Cu}^{2+}, \mathrm{Co}^{2+}$ and $\mathrm{Ni}^{2+}$ ions removal from aqueous solution using a novel chitosan/clinoptilolite composite: Kinetics and isotherms. Chemical Engineering Journal, 160, 157163 (2010). DOI: $10.1016 /$ j.cej.2010.03.029

[28] Murugesan A., Ravikumar L., SathyaSelvaBala V., SenthilKumar P., Vidhyadevi T., Dinesh Kirupha S., Kalaivani S. S., Krithiga S., Sivanesan S.: Removal of $\mathrm{Pb}$ (II), $\mathrm{Cu}(\mathrm{II})$ and $\mathrm{Cd}(\mathrm{II})$ ions from aqueous solution using polyazomethineamides: Equilibrium and kinetic approach. Desalination, 271, 199-208 (2011). DOI: $10.1016 /$ j.desal.2010.12.029
[29] Chaisuwan T., Komalwanich T., Luangsukrerk S., Wongkasemjit S.: Removal of heavy metals from model wastewater by using polybenzoxazine aerogel. Desalination, 256, 108-114 (2010). DOI: $10.1016 /$ j.desal.2010.02.005

[30] Shreedhara-Murthy R. S., Ryan D. E.: Preconcentration of copper, cadmium, mercury and lead from sea and tap water samples on a dithiocarbamatecellulose derivative. Analytica Chimica Acta, 140, 163-169 (1982).

DOI: $10.1016 / \mathrm{S} 0003-2670(01) 95461-3$

[31] Roozemond D. A., den Hond F., Veldhuis J. B. J., Strasdeit H., Driessen W. L.: Preferred uptake of Cu(II) and $\mathrm{Cd}(\mathrm{II})$ by novel pyrazole-functionalized chelating polymers. European Polymer Journal, 24, 867-872 (1988).

DOI: 10.1016/0014-3057(88)90161-9

[32] Say R., Garipcan B., Emir S., Patır S., Denizli A.: Preparation and characterization of the newly synthesized metal-complexing-ligand $N$-methacryloylhistidine having PHEMA beads for heavy metal removal from aqueous solutions. Macromolecular Materials and Engineering, 287, 539-545 (2002).

DOI: $10.1002 / 1439-2054(20020801) 287: 8<539:: A I D-$ MAME539>3.0.CO;2-O

[33] Kara A., Uzun L., Beşirli N., Denizli A.: Poly(ethylene glycol dimethacrylate- $n$-vinyl imidazole) beads for heavy metal removal. Journal of Hazardous Materials, 106, 93-99 (2004).

DOI: $10.1016 /$ j.jhazmat.2003.08.016

[34] Duran A., Soylak M., Tuncel S. A.: Poly(vinyl pyridine-poly ethylene glycol methacrylate-ethylene glycol dimethacrylate) beads for heavy metal removal. Journal of Hazardous Materials, 155, 114-120 (2008). DOI: $10.1016 /$ j.jhazmat.2007.11.037 